\title{
Genetic Parameters in IWD and IWF Strains of White Leghorn
}

\author{
Sridevi Boddana ${ }^{1 *}$, Viroji Rao Shinde ${ }^{2}$ and Gnana Prakash Manthani ${ }^{3}$ \\ ${ }^{1}$ Deptartment of Animal Genetics and Breeding, P.V. Narsimha Rao Telangana Veterinary University, Hyderabad, \\ Telangana, India \\ ${ }^{2}$ Registrar, P.V. Narsimha Rao Telangana Veterinary University, Hyderabad, Telangana, India \\ ${ }^{3}$ Professor and University Head, Deptartment of Animal Genetics and Breeding, P.V. Narsimha Rao Telangana Veterinary \\ University, Hyderabad, Telangana, India \\ *Corresponding author: S Boddana; E-mail: sridevivet@gmail.com
}

Received: 19 Aug., 2021

Revised: 22 Sept., 2021

Accepted: 26 Sept., 2021

\begin{abstract}
A total of 3150 progenies covering nine generations $\left(\mathrm{S}_{1}\right.$ to $\left.\mathrm{S}_{9}\right)$ at AICRP, Hyderabad were considered for the study. The heritability estimates in both the strains for AFE, egg weight, egg production at 28, 40, 64 weeks and body weights at different ages studied. The heritability value for AFE was found to be $0.07 \pm 0.10$ in IWD and $-0.04 \pm 0.07$ in IWF strains. The heritability for EP 64 was $0.050 \pm 0.10 \mathrm{in} \mathrm{IWD} \mathrm{and} \mathrm{in} \mathrm{IWF} 0.04 \pm 0.07$. The heritability values for body weight at 64 weeks were $0.02 \pm 0.07$ in IWF and $0.112 \pm 0.078$ in IWD. The results of the study suggested that the heritability of egg weight varied widely among the strains but it was low to moderate indicates the additive genes as well as favorable environment facilitate the improvement in the trait.
\end{abstract}

\section{HIGHLIGHTS}

(0 Well conducted selection experiments are useful in testing the validity of modern selection theory.

(0 Egg production up to 64 weeks of age was found to be low to moderately heritable.

(0 The heritability of egg weight varied widely among the strains.

Keywords: Heritability, IWD, IWF, White leghorn.

High genetic gain can be achieved when reliable breeding values are available for the relevant traits at an early age of selection candidates. This requires however a population management strategy that achieves high selection intensities and sufficiently short generation interval but ensures the maintenance of high genetic balance of the breed (Robin Wellman and Jorn Bennewitz, 2019). Heritability estimates and correlations among different production and reproduction traits are used to plan for future selection and breeding programmes and to estimate the genetic progress. Selection plays a major role in improvement in production efficiency of layers which brings change in gene and genotype frequencies in a population. Quantitative genetic methods effectively regard the animal as a black box with many genes contributing to the expression of all traits under selection. Selection brings change in gene and genotype frequencies in a population. Well conducted selection experiments are useful in testing the validity of modern selection theory.

The knowledge of basic genetic parameters like heritability, repeatability and correlation are of paramount importance to formulate effective breeding plans for improving the economic traits through selection. The rate of genetic improvement would depend on the estimates of heritability of the trait / traits for which individuals selected. Hatch corrected data were used to estimate the heritability values. Significant strain differences were observed for all the parameters studied.

How to cite this article: Boddana, S., Shinde, V.R. and Manthani, G.P (2021). Genetic Parameters in IWD and IWF Strains of White Leghorn. J. Anim. Res., 11(05): 869-873.

Source of Support: None; Conflict of Interest: None 


\section{MATERIALS AND METHODS}

The present investigation was carried out on two strains of White Leghorns viz., IWD, IWF maintained at AICRP on poultry, Hyderabad. The two strains of white leghorn chicken IWD, IWF utilized in the present study were selected for higher egg performance based on part year egg production upto 40 weeks age by employing Osborne index for 16 generations in IWD and 15 generations in IWF from 1971 to 1992 . After 16 generations of Osborne index selection based on part year egg production selection criteria was shifted to annual egg production 64 weeks of age (EP64) in the year 1992 and since then completed 9 generations of selection. The data on age at first egg (AFE), body weight at 16, 40 and 64 weeks, egg weight at 28 and 40 weeks of age and egg production at 40 and 64 weeks of age were recorded; erratic data from some progeny was omitted. In each generation 50 sires and 300 dams were selected a total of 350 birds were used. The data were analyzed by a statistical procedure "Least Squares Analysis" as explained by Harvey (1990).

Since the data were collected from birds produced in different hatches in each generation, the data was adjusted for significant hatch effects as per Harvey (1990) and the hatch corrected data were utilized for further statistical analysis.

Heritability, genetic, phenotypic and environmental correlations were estimated by full sib correlation method using mixed model least squares and maximum likelihood (LSMLMW) computer program (Harvey, 1990). The statistical model for the estimation of heritability of various traits studied was as follows:

$$
Y_{i j k}=\mu+s_{i}+d_{i j}+e_{i j k}
$$

where,

$$
\begin{aligned}
& Y_{i j k}=\text { Measurement of a trait on } k^{\text {th }} \text { progeny belonging to } \\
& j^{\text {th }} \text { dam mated to } i^{\text {th }} \text { sire. } \\
& \mu=\text { Overall mean } \\
& s_{i}=\text { effect of } i^{\text {th }} \text { sire } \\
& d_{i j}=\text { effect of } j^{\text {th }} \text { dam mated to the } i^{\text {th }} \text { sire } \\
& e_{i j k}=\text { uncontrolled environmental and genetic deviations } \\
& \text { attributable to the individuals }
\end{aligned}
$$

\section{RESULTS AND DISCUSSION}

The heritability estimates along with their standard errors for various economic traits of layer under the study in all the generations are presented in Table $1 \& 2$.

\section{Age at first egg}

The heritability estimate for age at first egg estimated from sire component of variance ranged from $-0.056 \pm 0.03$ to $0.43 \pm 0.10$ in IWD and $-0.01 \pm 0.05$ to $0.22 \pm 0.07$ in IWF. The values estimated through dam component of variance ranged from $-0.037 \pm 0.08$ to $0.239 \pm 0.09$ in IWD and $-0.26 \pm 0.08$ to $0.20 \pm 0.10$ in IWF. While the estimates by sire + dam component ranged from $0.024 \pm 0.03$ to 0.197 \pm 0.06 in IWD and $-0.10 \pm 0.04$ to $0.21 \pm 0.05$ in IWF respectively across nine generations.

The age at first egg was moderate to highly heritable trait. The values estimated age at first egg through sire dam component of variance varied from $0.024 \pm 0.034$ in $\mathrm{S}_{3}$ generation to $0.197 \pm 0.063$ in $\mathrm{S}_{5}$ in IWD and $-0.10 \pm 0.04$ in $S_{1}$ to $0.21 \pm 0.05$ (S2) in IWF. The differences between generations for heritability estimates of AFE were non significant. Similar observations for the heritability estimates were made by several authors, (Devi et al., 1998; Sing et al., 2002; Sharma et al., 2002 Kumar et al. 2004; Chatterjee et al., 2008; Jayalaxmi 2008; Veeramani et al., 2008; Anees et al., 2010; Sreenivas et al., 2012). Some reports indicated a higher values by sire + dam component of variance (Singh et al., 2001; Vasu et al., 2004; Sethi et al., 2003; Veeramani et al., 2008; Quadri et al., 2013). The heritability value estimated from sire + dam component in the present study for AFE indicated that it was low to moderately heritable. It could be concluded that accurate recording of age at first egg in individual rearing birds increased the precision in the heritability estimate of the AFE. It indicates greater role of environmental variance than additive genetic variance.

\section{Bodyweights}

The heritability estimate of Bodyweight 16, 40 and 64 weeks along with standard error are presented in table 1 $\& 2$. The estimated values by sire component variance method for body weight at 16 weeks of age across the nine generations ranged from $0.064 \pm 0.04$ to $0.341 \pm 0.09$ in IWD and $-0.03 \pm 0.05$ to $0.40 \pm 0.11$ in IWF, whereas by 
Table 1: Heritability estimates for various traits in IWD strain

\begin{tabular}{|c|c|c|c|c|c|c|c|c|c|}
\hline \multicolumn{10}{|c|}{$\begin{array}{l}\text { Gen. } \\
\text { No. }\end{array}$} \\
\hline & AFE & BW16 & BW40 & BW64 & EW28 & EW40 & EW64 & Ep40 & Ep64 \\
\hline $\mathrm{S}_{1}$ & $0.056 \pm 0.063$ & $0.194 \pm 0.072$ & $0.151 \pm 0.069$ & $0.078 \pm 0.066$ & $0.078 \pm 0.065$ & $0.115 \pm 0.066$ & $0.215 \pm 0.049$ & $0.066 \pm .063$ & $0.061 \pm 0.063$ \\
\hline $\mathrm{S}_{2}$ & $0.173 \pm 0.044$ & $0.275 \pm 0.052$ & $0.324 \pm 0.055$ & $0.230 \pm 0.049$ & $0.487 \pm 0.082$ & $0.477 \pm 0.079$ & $0.388 \pm 0.069$ & $0.289 \pm 0.052$ & $0.267 \pm 0.054$ \\
\hline $\mathrm{S}_{3}$ & $0.024 \pm 0.034$ & $0.279 \pm 0.059$ & $0.012 \pm 0.034$ & $0.012 \pm 0.032$ & $0.363 \pm 0.072$ & $0.419 \pm 0.075$ & $0.190 \pm 0.049$ & $0.119 \pm 0.042$ & $0.112 \pm 0.042$ \\
\hline $\mathrm{S}_{4}$ & $0.177 \pm 0.049$ & $0.064 \pm 0.043$ & $0.028 \pm 0.041$ & $0.059 \pm 0.042$ & $0.288 \pm 0.061$ & $0.275 \pm 0.059$ & $0.130 \pm 0.048$ & $0.029 \pm 0.041$ & $0.051 \pm 0.042$ \\
\hline $\mathrm{S}_{5}$ & $0.197 \pm 0.063$ & $0.074 \pm 0.049$ & $0.114 \pm 0.049$ & $0.267 \pm 0.058$ & $0.303 \pm 0.062$ & $0.278 \pm 0.060$ & $0.166 \pm 0.052$ & $0.129 \pm 0.049$ & $0.047 \pm 0.047$ \\
\hline $\mathrm{S}_{6}$ & $0.090 \pm 0.053$ & $0.045 \pm 0.049$ & $0.146 \pm 0.056$ & $0.064 \pm 0.050$ & $0.258 \pm 0.064$ & $0.218 \pm 0.064$ & $0.161 \pm 0.057$ & $0.095 \pm 0.054$ & $0.063 \pm 0.052$ \\
\hline $\mathrm{S}_{7}$ & $0.074 \pm 0.054$ & $0.108 \pm 0.056$ & $0.085 \pm 0.055$ & $0.137 \pm 0.058$ & $0.223 \pm 0.065$ & $0.250 \pm 0.066$ & $0.309 \pm 0.069$ & $0.157 \pm 0.059$ & $0.001 \pm 0.049$ \\
\hline $\mathrm{S}_{8}$ & $0.053 \pm 0.052$ & $0.122 \pm 0.056$ & $0.106 \pm 0.055$ & $0.273 \pm 0.066$ & $0.082 \pm 0.046$ & $0.288 \pm 0.066$ & $0.105 \pm 0.055$ & $0.094 \pm 0.054$ & $0.015 \pm 0.050$ \\
\hline $\mathrm{S}_{9}$ & $0.07 \pm 0.10$ & $0.043 \pm 0.194$ & $0.256 \pm 0.151$ & $0.112 \pm 0.078$ & $0.078 \pm 0.043$ & $0.142 \pm 0.115$ & $0.010 \pm 0.100$ & $0.060 \pm 0.10$ & $0.05 \pm 0.10$ \\
\hline
\end{tabular}

Table 2: Heritability estimates for various traits in IWF strain

\begin{tabular}{|c|c|c|c|c|c|c|c|c|c|}
\hline Gen. No & AFE & BW 16 & BW 40 & BW 64 & Ew28 & Ew40 & Ew64 & Ep40 & Ep64 \\
\hline $\mathrm{S}_{1}$ & $-0.10 \pm 0.04$ & $-0.06 \pm 0.04$ & $0.06 \pm 0.05$ & $0.01 \pm 0.04$ & $-0.04 \pm 0.04$ & $-0.08 \pm 0.04$ & $-0.10 \pm 0.04$ & $-0.08 \pm 0.04$ & $-0.10 \pm 0.04$ \\
\hline $\mathrm{S}_{2}$ & $0.21 \pm 0.05$ & $0.36 \pm 0.06$ & $0.26 \pm 0.05$ & $0.25 \pm 0.05$ & $0.32 \pm 0.06$ & $0.32 \pm 0.06$ & $0.36 \pm 0.06$ & $0.15 \pm 0.04$ & $0.10 \pm 0.04$ \\
\hline $\mathrm{S}_{3}$ & $0.18 \pm 0.04$ & $0.20 \pm 0.04$ & $0.37 \pm 0.06$ & $0.26 \pm 0.05$ & $0.32 \pm 0.06$ & $0.22 \pm 0.05$ & $0.15 \pm 0.04$ & $0.22 \pm 0.05$ & $0.12 \pm 0.04$ \\
\hline $\mathrm{S}_{4}$ & $0.14 \pm 0.05$ & $0.05 \pm 0.04$ & $-0.01 \pm 0.04$ & $0.12 \pm 0.05$ & $0.17 \pm 0.05$ & $0.02 \pm 0.04$ & $0.23 \pm 0.05$ & $0.08 \pm 0.05$ & $0.15 \pm 0.05$ \\
\hline $\mathrm{S}_{5}$ & $0.14 \pm 0.05$ & $0.22 \pm 0.06$ & $0.14 \pm 0.05$ & $0.04 \pm 0.05$ & $0.11 \pm 0.05$ & $0.09 \pm 0.05$ & $0.18 \pm 0.05$ & $0.39 \pm 0.07$ & $0.17 \pm 0.05$ \\
\hline $\mathrm{S}_{6}$ & $-0.02 \pm 0.04$ & $-0.03 \pm 0.04$ & $0.21 \pm 0.05$ & $0.01 \pm 0.04$ & $0.22 \pm 0.06$ & $0.19 \pm 0.06$ & $0.04 \pm 0.04$ & $0.04 \pm 0.04$ & $-0.08 \pm 0.04$ \\
\hline $\mathrm{S}_{7}$ & $0.12 \pm 0.05$ & $0.05 \pm 0.04$ & $0.14 \pm 0.05$ & $0.21 \pm 0.06$ & $0.31 \pm 0.07$ & $0.19 \pm 0.06$ & $0.04 \pm 0.04$ & $0.08 \pm 0.04$ & $0.14 \pm 0.05$ \\
\hline $\mathrm{S}_{8}$ & $0.01 \pm 0.07$ & $0.06 \pm 0.07$ & $0.17 \pm 0.07$ & $0.25 \pm 0.08$ & $-0.17 \pm 0.06$ & $-0.05 \pm 0.07$ & $0.13 \pm 0.07$ & $0.12 \pm 0.07$ & $0.04 \pm 0.07$ \\
\hline $\mathrm{S}_{9}$ & $-0.04 \pm 0.07$ & $-0.06 \pm 0.07$ & $0.33 \pm 0.09$ & $0.02 \pm 0.07$ & $0.00 \pm 0.07$ & $0.31 \pm 0.09$ & $0.00 \pm 0.07$ & $0.00 \pm 0.07$ & $0.04 \pm 0.07$ \\
\hline
\end{tabular}

dam component variance the values ranged from $0.04 \pm$ 0.09 to $0.34 \pm 0.08$ in IWD and $-0.20 \pm 0.14$ to $0.35 \pm 0.11$ in IWF. The estimates by sire+dam component ranged from $0.043 \pm 0.19$ to $0.27 \pm 0.05$ in IWD and $-0.06 \pm 0.04$ to $0.36 \pm 0.06$ in IWF.

Body weight at 40 weeks of age was found to be low to moderately heritable ranging from $-0.008 \pm 0.02$ to 0.18 $\pm 0.11,-0.009 \pm 0.07$ to $0.460 \pm 0.09$ and $0.012 \pm 0.03$ to $0.32 \pm 0.05$ in IWD and $-0.07 \pm 0.03$ to $0.30 \pm 0.10$, $-0.11 \pm 0.09$ to $0.45 \pm 0.10$ and $-0.01 \pm 0.04$ to $0.37 \pm$ 0.06 in IWF when estimated from sire, dam and sire + dam components of variance, respectively.

The computed heritability values for body weight at 64 weeks of age ranged from $-0.04 \pm 0.03$ to $0.27 \pm 0.09$, $-0.043 \pm 0.06$ to $0.377 \pm 0.12$ and $-0.012 \pm 0.03$ to $0.27 \pm$ 0.06 in IWD through sire, dam and sire + dam components of variance, respectively where as the corresponding values in IWF were $-0.05 \pm 0.05$ to $0.27 \pm 0.08,-0.09 \pm$ 0.09 to $0.33 \pm 0.09$ and $0.01 \pm 0.04$ to $0.26 \pm 0.05$. In the present study, heritability of body weight at 16, 40 and 64 weeks of age varied both in magnitude and trend based on the component of variance. Estimates from sire + dam component indicated the trait at all ages showed low to moderately heritability. In contrast to the above findings earlier studies (Veeramani et al., 2008; Anees et al., 2010; Quadri et al., 2013) reported higher heritability values by sire+dam component of variance for body weight at 16 weeks. Slight differences between generations for heritability across generations were observed in the study which was in accordance with previous reports (Bais et al., 1997; Vasu et al., 2004; Chatterjee et al., 2008; Jayalaxmi, 2008). Few authors (Veeramani et al., 2008; Anees et al., 2010; Veeramani et al., 2012; Sreenivas et al., 2012; 
Quadri et al., 2013) reported higher estimates by sire+dam component of variance for body weight at 40 weeks.

Some reports (Jayalaxmi et al., 2008; Veeramani et al., 2012; Sreenivas et al., 2012) indicated higher heritability also for body weight at 64 weeks from sire+dam component of variance. The results showed that the body weight in general was low to moderate heritable trait at all the ages indicating additive genetic variance has important role in governing the expression of the trait at all the age.

\section{Egg production traits}

The heritability estimates of egg production traits along with their standard errors are presented in tables $1 \& 2$.

The estimates through sire, dam and sire + dam component for egg weight at 28 weeks ranged from $-0.062 \pm 0.047$ to $0.58 \pm 0.14,-0.302 \pm 0.08$ to $0.384 \pm 0.08$ and $-0.082 \pm$ 0.046 to $0.48 \pm 0.08$ in IWD and $0.04 \pm 0.06$ to $0.43 \pm$ $0.11,-0.44 \pm 0.12$ to $0.34 \pm 0.09$ and $-0.17 \pm 0.06$ to 0.32 \pm 0.06 in IWF respectively.

For egg weight at 40 weeks it ranged from $-0.018 \pm 0.05$ to $0.548 \pm 0.14,0.157 \pm 0.12$ to $0.525 \pm 0.13,0.115 \pm 0.06$ to $0.477 \pm 0.07$ in IWD from sire, dam and sire + dam components of variance and the corresponding values in IWF were $0.02 \pm 0.03$ to $0.41 \pm 0.13,-0.18 \pm 0.09$ to 0.28 $\pm 0.08,-0.08 \pm 0.04$ to $0.32 \pm 0.06$.

The heritability of egg weight at 64 weeks estimated from sire, dam and sire + dam component of variance ranged from $0.031 \pm 0.05$ to $0.460 \pm 0.12,-0.480 \pm 0.10$ to 0.473 $\pm 0.13,-0.215 \pm 0.04$ to $0.388 \pm 0.06$ in IWD and $-0.06 \pm$ 0.05 to $0.44 \pm 0.12,-0.19 \pm 0.09$ to $0.28 \pm 0.08,-0.1 \pm 0.04$ to $0.36 \pm 0.06$ in IWF.

The results revealed that egg weight was moderate to high heritable character at all the ages in all the generations indicating higher role of additive genetic variance and phenotypic expression of the traits. The study revealed that the higher estimates obtained by sire + dam component for egg weight at 28, 40, and 64 weeks.

Heritability of egg production up to 40 weeks of age was found to be low to moderate ranging from $0.034 \pm 0.049$ to $0.192 \pm 0.06,-0.049 \pm 0.07$ to $0.396 \pm 0.09,0.029 \pm 0.04$ to $0.289 \pm 0.05$ in IWD and $-0.15 \pm 0.04$ to $0.21 \pm 0.07$,
$-0.93 \pm 0.15$ to $0.28 \pm 0.16,-0.08 \pm 0.04$ to $0.39 \pm 0.07$ in IWF respectively, when estimated from sire, dam and sire + dam components of variance.

Egg production up to 64 weeks of age was found to be low to moderately heritable and ranged from $-0.0220 \pm 0.03$ to $0.283 \pm 0.08,-0.065 \pm 0.10$ to $0.25 \pm 0.07,0.001 \pm 0.04$ to $0.267 \pm 0.05$ and $-0.01 \pm 0.04$ to $0.14 \pm 0.05,-0.24 \pm 0.08$ to $0.37 \pm 0.12,-0.1 \pm 0.04$ to $0.17 \pm 0.05$ in IWF when estimated from sire, dam and sire + dam components of variance, respectively. The heritability estimates for egg number showed no significant differences between generations. As egg production is a closely associated trait with reproductive fitness, low estimate was expected. Smaller standard errors of estimates showed greater precision of estimates. These results are concurrent with reports of Bais et al. (1997); Brah et al. (1998); Vasu et al. (2004); Chatterjee et al. (2008); Anees et al. (2010); Jayalaxmi (2008); Veeramani et al. (2012); Sreenivas et al. (2012); Quadri et al. (2013).

In general the heritability of a trait will vary across populations, measurement devices, choice of scale and countless environmental factors.

The very possibility of negative heritability depends strongly on the nature of the trait of the population and of the sampling procedure.

Statistical models of convenience such as the variance component model that underlies GREML and many other heritability estimation approaches should never drive substantive conclusions, such as declaring that negative heritability is impossible (David steinsaltz et al., 2020).

\section{CONCLUSION}

The heritability estimates in both the strains were low for AFE and egg weight, egg production at 40, 64 weeks, while they were low to medium for body weights at different ages studied.

\section{ACKNOWLEDGEMENTS}

I would like to thank the staff of AICRP on poultry, Hyderabad for their help and support in conducting the research work. 


\section{REFERENCES}

Anees, C., Veeramani, P., Narayanankutty, K., Ani, B. and Riyas, M.A. 2010. Estimation of genetic and phenotypic parameters of economic traits in White Leghorn. Indian J. Poult. Sci., 45(1): 14-17.

Bais, R.K.S., Johari, D.C., Hazary, R.C., Kataria, M.C., Sharma, D. and Sharma, R.D. 1997. Inheritance of important economic traits in IWH strain of white Leghorn under reciprocal recurrent selection. Indian J. Poult. Sci., 32(2): 189-191.

Brah, G.S., Chaudhary, M.L. and Sandhu, J.S. 1998. Inheritance of shell-quality related egg traits at two stages in the early part of laying in chickens. Indian J. Poult. Sci., 33(3): 309316.

Chatterjee, R.N., Niranjan, M., Panda, A.K., Reddy, B.L.N., Branja, S.K. and Singh, D. 2000. Inheritance of important economic traits in 3 pure lines and a control population of White Leghorn. Indian J. Anim. Sci., 78: 75-79.

David, S., Andy, D., Kenneth, W. and Wachter. 2020. On negative heritability and negative estimates of heritability. Genetics, 215: 343-357.

Devi, K., Sreerama Murthy, A., Prasad, V.L.K., Eswara Reddy, C., Mahipal Reddy, P., Ramesh Gupta, B. and Satyanarayana, A. 1998. Genetic studies on certain parameters of egg quality in White Leghorn. Indian J. Poult. Sci., 33(1): 81-85.

Harvey, W.R. 1999. User's guide. LSMLMW and MIXMDL PC-2 version. Mixed model least-squares and maximum likelihood computer programme. Ohio, USA.

Jayalaxmi, P. 2008. Genetic analysis of various productive and immunocompetence traits in White Leghorns under long term selection. Ph.D. thesis submitted to Sri Venkateswara Veterinary University, Tirupati.

Kumar, G.G., Reddy, P.M., Gupta, B.R. and Praharaj, N.K. 2004. Relative efficiency of selection based on segments of the part record to improve annual egg production in White Leghorns. Indian J. Poult. Sci., 39(3): 224-228.
Quadri, F.S., Savaliya, F.P., Patel, A.B., Joshi, R.S., Hirani, N.D. and Patil, S.S. 2013. Genetic study on important economic traits in two strains of white leghorn chicken. Indian J. Poult. Sci., 48(2): 149-153.

Robin W. and Jorn B. 2019. Key genetic parameters for population management. Front. Genet., 667(10): 1-20.

Sethi, S., Mishra, P.K., Mishra, S.C. and Dehuri, P.K. 2003. Genetic characterization of a White Leghorn population for some production traits. J. Poult. Sci., 38: 277-280.

Sharma, P.K., Varma, S.K., Sharma, R.K. and Brijesh, S. 2002. Inheritance of body weights and egg production in White Leghorn. Indian J. Poult. Sci., 37: 172-174.

Singh, B.S., Chhikara, D.S., Dalal, D.S. and Malik, C.P. 2001. Estimation of genetic and phenotypic parameters of economic traits of White Leghorn. Indian J. Poult. Sci., 36: 163-168.

Singh, U.B., Chhikara, B.S. and Raheja, K.L. 2002. Estimation of genetic parameters of various economic traits over different generations of selection in a closed population of White Leghorn. Indian J. Poult. Sci., 37: 135-138.

Sreenivas, D., Prakash, M. G., Chatterjee, R. N. and Mahender, M. 2012. Genetic analysis of productive and reproductive traits in White Leghorn chicken. Indian J. Poult. Sci., 47(3): 274-280.

Vasu, Y., Rao, G. N., Sharma, R. P., Hazary, R.C., Gupta, B. R. and Satyanarayana, A. 2004. Genetic study on egg production traits in IWI and control strains of White Leghorn. Indian J. Anim. Sci., 74: 994-996.

Veeramani, P., Narayanankutty, K. and Churchil, R.R. 2008. Estimation of heritability and correlation of economic traits in IWP strain of White Leghorn chicken. Indian J. Anim. Res., 42(4): 257-260. 
